\title{
Антимикробная химиотерапия пневмонии в амбулаторных условиях: медицинские и социально-экономические аспекты
}

ГОУ ВПО "Казанский государственный медицинский университет", кафедра внутренних болезней № 2: 420012, Республика Татарстан, Казань, ул. Бутлерова, 49

\section{R.F.Khamitov, Z.N.Yakupova \\ Antibacterial treatment of the outpatienty̌s pneumonia: medical, social and economical aspects}

\begin{abstract}
Summary
Questioning of 32 doctors of polyclinics of Kazan and Zelenodolsk about treatment of 216 patients with community acquired pneumonia was done. As a whole doctors have shown not bad level of knowledge of the given problem. Analysis of the widespread mistakes will allow to improve further medical approaches to management of this pathology.

Key words: questionnaire, community acquired pneumonia, antibacterial treatment.
\end{abstract}

\section{Резюме}

Было проведено анкетирование 32 врачей поликлиник Казани и Зеленодольска по антимикробному лечению 216 пациентов с внебольничной пневмонией. В целом врачи показали неплохой уровень знаний по данной проблеме. Разбор распространенных ошибок позволит и дальше совершенствовать лечебные подходы к ведению этой патологии.

Ключевые слова: анкетирование, внебольничная пневмония, антимикробная терапия.

В структуре заболеваемости взрослых существенное значение на сегодняшний день имеет респираторная патология. Внебольничная пневмония (ВП) является одной из ведущих причин смерти среди заболеваний нижних дыхательных путей. В 2006 г. в РФ было официально зарегистрировано 414,3 случаев пневмонии на 100 тыс. населения [1]. По всей видимости, реальное число больных пневмонией значительно выше. Для своевременной диагностики, адекватного лечения и уменьшения летальных исходов пневмонии большую роль играет высокий профессиональный уровень лечащих врачей.

В современных условиях большинство случаев ВП имеет нетяжелое течение и не требует госпитализации. Таким образом, ведущая роль в лечении пациентов с ВП принадлежит врачам поликлинического звена, качество работы которых и, в первую очередь, проведение адекватной своевременной антимикробной терапии во многом определяет течение и исход болезни.

В рамках проспективного многоцентрового фармакоэпидемиологического исследования по оценке лечения ВП у взрослых пациентов в амбулаторных условиях, проводимого НИИ антимикробной химиотерапии и кафедрой клинической фармакологии СГМА, в ряде городских поликлиник Республики Татарстан (Казани и Зеленодольска) было проведено изучение существующей практики назначения антимикробных препаратов (АМП) пациентам с ВП, анализ социальных, медицинских и экономических аспектов, оказывающих влияние на выбор АМП.
С этой целью было проведено анкетирование 32 поликлинических терапевтов. Средний возраст респондентов составил 44,63 \pm 1,74 года. Все врачи имели практический опыт лечения ВП и достаточный стаж лечебной работы (в среднем, 11 лет). 59 \% врачей прошли очередную учебу в рамках повышения квалификации в течение последних 3 лет, не было ни одного, кто бы не обучался в течение последних 5 лет. Таким образом, анкетирование проводилось среди лиц с достаточной теоретической и практической базой знаний.

Были проанализированы 216 случаев ВП, пролеченной данными врачами. Средний возраст пациентов составил 53,22 \pm 1,24 года, большинство больных были представлены лицами мужского пола (60\%), состояли в браке (64\%), имели среднее или среднее специальное образование (72 \%). Среди больных преобладали лица, имеющие рабочие профессии (36\%), и пенсионеры или инвалиды (31\%). Более половины пациентов (56 \%) имели среднемесячный доход на 1 члена семьи от 2 до 5 тыс. рублей. В основном все пациенты (96 \%) заболели пневмонией впервые за текущий год, т. е. не относились к категории часто болеющих.

К индикаторам, используемым в России для оценки качества оказания медицинской помощи взрослым пациентам с ВП, относятся, в первую очередь, своевременность и адекватность антибактериальной терапии. Представлялось интересным изучение предпочтений амбулаторно-поликлинических врачей различных АМП и режимов терапии и осо- 
бенно аргументации ими своей лечебной тактики. Подобные исследования, верифицирующие роль Национальных рекомендаций по диагностике и лечению различных нозологий в реальной клинической практике, имеют важное значение для дальнейшего совершенствования лечебно-диагностических подходов, выявления причин и структуры врачебных ошибок в регионе с последующей целенаправленной работой по их устранению и профилактике [2, 3].

Для лечения в амбулаторных условиях пациентов моложе 60 лет с ВП без значимой сопутствующей патологии в качестве инициальных антибактериальных препаратов выбора рекомендованы амоксициллин внутрь и макролиды с улучшенными фармакокинетическими свойствами (азитромицин, кларитромицин, джозамицин) внутрь. У пациентов старше 60 лет и / или при наличии сопутствующих заболеваний начинать антимикробную терапию в амбулаторных условиях необходимо с перорального назначения амоксициллина / клавуланата [4, 5].

Результаты опроса показали приверженность большинства участковых терапевтов федеральным и республиканским рекомендациям по лечению ВП (рис. 1). Это подтверждают и пациенты, получавшие АМП, назначенные им для лечения пневмонии более года тому назад, такие как азитромицин, кларитромицин, амоксициллин и амоксициллин / клавуланат.

Однако следует заметить, что $41 \%$ опрошенных врачей указывали ципрофлоксацин в качестве предпочтительного АМП для лечения пневмонии в амбулаторных условиях, и 1,5 \% пациентов помнили, что именно он назначался им для лечения предыдущих пневмоний. $26 \%$ участковых терапевтов в рубрике "другие препараты" называли цефазолин и цефоперазон. Эти факты должны вызывать тревогу.

Ципрофлоксацин (фторхинолон II поколения) и цефазолин (цефалоспорин I поколения) представлены в последних федеральных рекомендациях по лечению нетяжелой ВП в рубрике "Как не надо лечить внебольничную пневмонию" [5].

Существующая активность ципрофлоксацина против микобактерий и Pseudomonas aeruginosa возбудителя тяжелых госпитальных пневмоний при необоснованно широком применении может способствовать селекционированию устойчивых штаммов, а также затруднять своевременную диаг-

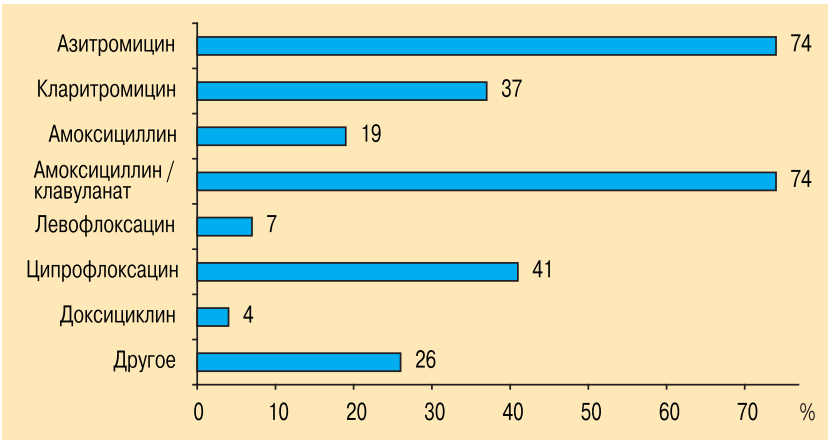

Рис. 1. Предпочтения терапевтов в АМП при амбулаторном лечении ВП ностику легочного туберкулеза. Также весьма актуальна недостаточная антипневмококковая активность ципрофлоксацина.

Антипневмококковая активность цефазолина уступает аминопенициллинам. Кроме того, цефазолин имеет клинически незначимую активность в отношении Haemophilus influenzae, наряду с пневмококком относящейся к распространенным возбудителям ВП.

Цефоперазон, как и цефтазидим, имеет меньшую антипневмококковую и повышенную антипсевдомонадную активность в сравнении с другими цефалоспоринами III поколения. Это исключает данный АМП из терапевтического арсенала при лечении ВП.

На эффективность терапии в амбулаторных условиях, в отличие от стационара, значительно большее влияние оказывает комплаентность пациента, т. е. точность следования врачебным рекомендациям. И здесь, среди факторов, определяющих комплантеность, помимо субъективных личностных характеристик больного, можно назвать и объективные, препятствующие проведению адекватной терапии. Сюда можно отнести стоимость препарата, неудобный для амбулаторных условий режим приема, частоту и выраженность побочных эффектов, длительность сроков лечения.

Несмотря на кажущуюся естественной рациональность применения в амбулаторных условиях пероральных форм препаратов, в т. ч. антимикробных, вызывает некоторое недоумение тот факт, что только $63 \%$ врачей назвали предпочтительным данный способ введения АМП. 30 \% указали, что используют как пероральные, так и парентеральные антибиотики. Если вспомнить о предпочтении цефазолина и цефоперазона и отсутствии упоминаний о цефтриаксоне как препарате выбора при лечении ВП, данный факт также вызывает тревогу. Известно, что только цефтриаксон - единственный из цефалоспоринов III генерации с возможностью однократного парентерального (в т. ч. внутримышечного) назначения в сутки - может в отдельных ситуациях быть использован для лечения пневмонии в амбулаторных условиях [4].

По результатам данного исследования было также выявлено, что на врача при выборе лекарственного средства в ряде случаев оказывает влияние сам пациент. Так число пациентов, предпочитающих инъекционную форму введения антибиотика (39 \%), мало отличалось от количества предпочитающих таблетированные препараты (53\%). При этом $85 \%$ опрошенных участковых терапевтов указали, что сталкиваются с требованием пациента назначить конкретный антибиотик. Следует также отметить, что только 48 \% поликлинических врачей самостоятельно обсуждают с больным аргументацию выбора того или иного АМП для лечения пневмонии, и этот показатель несомненно оказывает соответствующее воздействие на комплаентность назначений, а значит - и результаты лечения.

Для начала антимикробного лечения пневмонии весьма значима осознанность врачами выбора АМП. При неожиданно большом, как оказалось, 


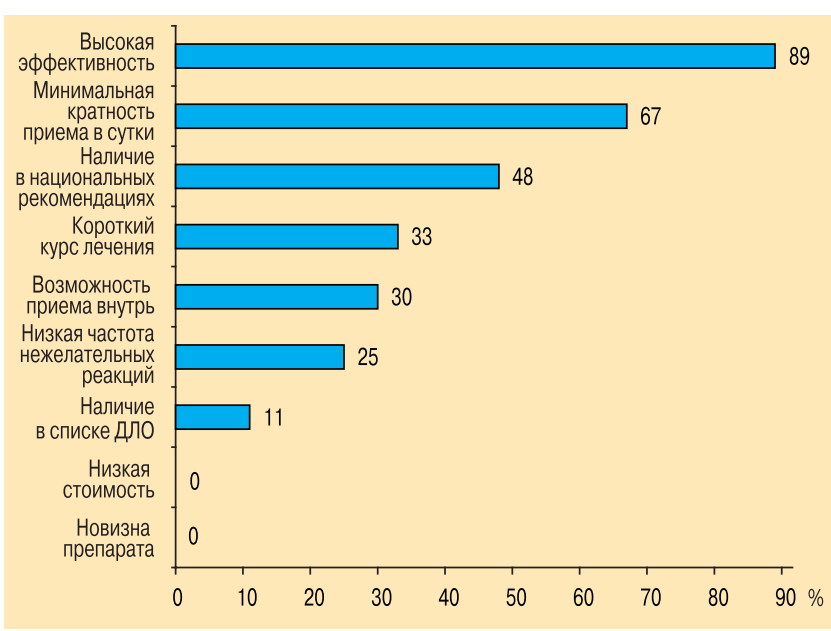

Рис. 2. Значимые критерии врачебного выбора АМП при лечении ВП

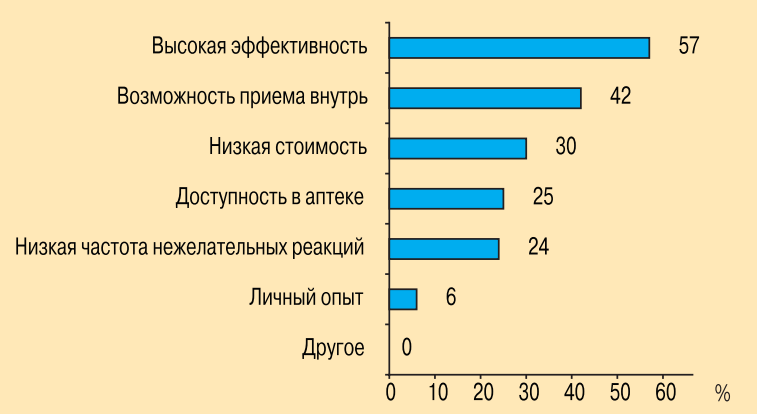

Рис. 3. Значимые для пациентов факторы выбора АМП при лечении ВП

воздействии со стороны пациентов ( $85 \%)$ на решение этого вопроса, важно не идти "на поводу" у больного и его родственников, не назначать препарат по факту его наличия в ближайшей аптеке, а осуществлять выбор, опираясь, в первую очередь, на действующие Федеральные и республиканские рекомендации.

Значимые, по результатам опроса, критерии выбора участковыми терапевтами АМП для лечения ВП представлены на рис. 2.

Интересно сравнение полученных данных (рис. 2) с предпочтениями пациентов по выбору АМП (рис. 3) с учетом выявленного у больных желания активно воздействовать на свое лечение.

Настораживает относительно невысокий процент значимости для врачей нежелательных реакций (25\%) и, хотя этот показатель должен иметь большое значение для комплаентности пациентов при амбулаторном лечении, на практике мнение пациентов оказалось примерно таким же (24\%). По всей видимости, дело здесь в достаточно высокой безопасности АМП в совокупности с доказанной эффективностью, являющейся основанием для включения их в федеральные и республиканские рекомендации по лечению пневмонии.

К сожалению, врачи недостаточно высоко оценивали значимость наличия АМП в национальных рекомендациях (48 \%), тогда как данный критерий относится к индикаторам качества ведения больных пневмонией. Недостаточная серьезность отношения поликлинических врачей к существующим стандартам (протоколам) диагностики и лечения пневмонии отражает и факт выбора участковыми терапевтами ципрофлоксацина в качестве предпочтительного препарата для амбулаторного лечения пневмонии в $26 \%$ случаев - одновременно с указанием в качестве значимого критерия выбора его "наличие в национальных рекомендациях", а в 33 \% - "высокую эффективность". Об эффективности ципрофлоксацина уже говорилось выше, это определило и его отсутствие в федеральных и республиканских рекомендациях по лечению пневмонии у взрослых в амбулаторных условиях $[4,5]$.

Неудивительно расхождение во мнениях врачей и пациентов в отношении значимости цены АМП. Необходимо акцентировать внимание на, пусть и небольшой по значимости, оценке пациентом личного опыта лечения пневмонии (6 \%). Этот опыт может проистекать из эффективности 1-го лечения заболевания врачом. Негативизм данного факта проявляется в том, что в последующем больной может самостоятельно выбрать тот же самый АМП, уже не обращаясь за помощью к врачу.

Результаты анкетирования участковых терапевтов на предмет основных источников информации об АМП показали высокую роль научно-практических конференций и круглых столов, просветительской работы медицинских представителей фармацевтических компаний и периодических медицинских изданий (рис. 4).

Не может не радовать тот факт, что в подавляющем большинстве случаев пациент получает информацию об АМП от своего врача, увеличивая тем самым вероятность благоприятного исхода ВП (рис. 5). Врачи должны помнить о значимости своих медикаментозных рекомендаций для пациентов и грамотно использовать свой авторитет и знания при организации лечебно-диагностического процесса, т. к. в про-

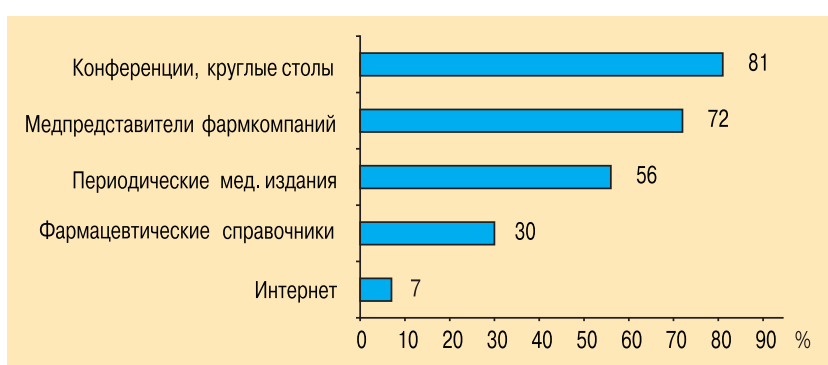

Рис. 4. Значимые для врачей источники информации об АМП

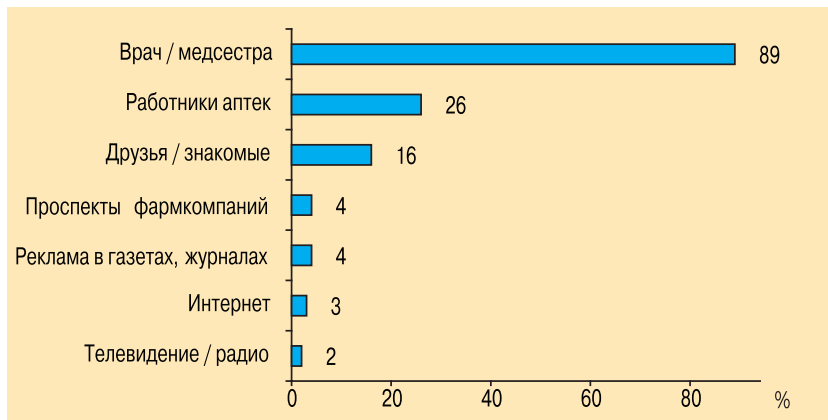

Рис. 5. Значимые для пациентов источники информации об АМП 
тивном случае, как видно из полученных данных, больных от пневмонии будут лечить аптечные работники и знакомые.

В 216 проанализированных случаях лечения пациентов с ВП необходимость в повторной антибактериальной терапии возникала лишь в $9 \%$ наблюдений, и в качестве основных критериев выбора препарата для продолжения лечения врачи называли клиническую неэффективность предшествующего антибиотика (73\%) и желание пациента (18\%). Последний факт вызывает определенную тревогу.

В структуре АМП, использованных для продолжения амбулаторного лечения, лидировали макролиды и цефалоспорины III поколения (по 34 \%), защищенные аминопенициллины занимали 3-е место $(10 \%)$.

Об успехе амбулаторного лечения ВП можно было судить по достаточно небольшому проценту госпитализированных пациентов (13\%). Однако критерию выздоровления, с точки зрения лечащих врачей, соответствовали лишь $71 \%$ реконвалесцентов.

\section{Заключение}

Полученные результаты исследования медицинских и социально-экономических аспектов антимикробной химиотерапии ВП в ряде поликлиник Республики Татарстан показали наряду с несомненными успехами пока еще недостаточный уровень знаний врачей амбулаторно-поликлинической службы тактики антибактериальной терапии ВП и позволяют наметить следующие перспективные направления совершенствования оказания медицинской помощи для данной категории пациентов:

1. Необходимо уделять особое внимание разработке и популяризации среди практических врачей стандартов (протоколов) диагностики и лечения ВП с привлечением к этому ведущих специалистов-экспертов, создавать эти стандарты доступными, понятными и отвечающими потребностям клиницистов.

2. Выявлена высокая значимость научно-практических конференций для врачей на местах как важного источника современных знаний в области антимикробной химиотерапии пневмонии. Необходимо регулярное проведение подобных мероприятий на высоком научно-методическом уровне с привлечением как ведущих специалистов в данной области, так и представителей ад- министративно-управленческого звена здравоохранения.

3. Необходимо повышение качества, доступности и привлекательности для практических врачей периодических медицинских изданий, а также правильная организация работы с фармацевтическими компаниями с сохранением возможности адекватной сравнительной оценки информации от компаний-конкурентов и собственного самостоятельного выбора.

4. В современных непростых социально-экономических условиях подтверждена значимость для пациента мнения врача в организации лечения пневмонии на амбулаторном этапе. В целях сохранения и укрепления данной позиции необходимо постоянное самообучение врачей, их приверженность индикаторам качества оказания медицинской помощи и, в первую очередь, федеральным и разработанным на их основе региональным протоколам ведения больных пневмонией.

\section{Литература}

1. Какорина Е.П., Михайлова Л.А., Огрызко Е.В. и др. Заболеваемость населения России в 2006 году: Статистические материалы. Часть I. М.; 2007.

2. Журавлева Т.А., Казанцева М.Е., Гришина В.А. Принципы наблюдения за пульмонологическими больными подросткового возраста в поликлинике. Пульмонология 2004; (4): 56-59.

3. Хамитов Р.Ф. Ведение пациента с пневмонией в амбулаторно-поликлинической практике и стационаре: мнения практикующих врачей. Вестник современной клинической медицины 2009; 2 (4): 55-59.

4. Хамитов Р.Ф. Клинические рекомендации по диагностике и лечению внебольничных пневмоний. В кн.: Клинические рекомендации врачу терапевту. Казань: ООО "Печатный двор"; 2008. 97-105.

5. Чучалин А.Г., Синопальников А.И., Рачина С.А. и др. План ведения больных нетяжелой внебольничной пневмонией. Врач 2009; специальный выпуск: 1-19.

\section{Информация об авторах}

Рустэм Фидагиевич Хамитов - д. м. н., проф., зав. кафедрой внутренних болезней № 2 ГОУ ВПО "Казанский государственный медицинский университет Росздрава"; тел.: +7-917-272-96-72; e-mail:rhamitov@ mail.ru

Зухайра Нафкатовна Якупова - доцент кафедры внутренних болезней № 2 ГОУ ВПО "Казанский государственный медицинский университет Росздрава"; тел.: +7-917-906-30-16

Поступила 09.02.10 (с) Хамитов Р.Ф., Якупова З.Н., 2010 УДК 616.24-002-085.28 